\title{
Ethnic labels, pride, and challenges: A qualitative study of Latinx youth living in a new Latinx destination community
}

\author{
Rosalie Corona, Ph.D. ${ }^{1}$ \\ Efren Velazquez, M.S. ${ }^{1}$ \\ Shelby E. McDonald, Ph.D. ${ }^{2}$ \\ Melissa Avila, B.A. ${ }^{1}$ \\ Molly Neff, Ph.D. ${ }^{1}$ \\ Adam Iglesias, Ph.D. ${ }^{1}$ \\ Raquel Halfond, Ph.D. ${ }^{1}$
${ }^{1}$ Department of Psychology, Virginia Commonwealth University, 806 W. Franklin Street, Richmond, VA, 23284 ${ }^{2}$ School of Social Work, Virginia Commonwealth University, 1000 Floyd Ave., \\ Richmond, VA 23284
}

\begin{abstract}
Most of the literature on Latinx youths' ethnic identity development has been conducted in communities with a large Latinx population. Fewer studies have examined Latinx youths' ethnic identity in communities with a smaller yet rapidly growing Latinx population (i.e., new Latinx destination communities). Twenty-five Latinx youth (10-15 years)living in a new Latinx destination community participated in semi-structured interviews to identify the ethnic labels they use to describe themselves (i.e., ethnic-identity self-identification) and explore their feelings about being Latinx (i.e., ethnic-identity affirmation). Using an existing coding scheme, we found that most immigrant youth used a national origin label alone, while U.S.-born youth used a pan-ethnic term alone or in combination with an American term. Results of the thematic analysis exploring youths' ethnic identity affirmation indicated three themes among youths' account of their ethnic affirmation: (a) pride; (b) communication difficulties; and (c) discrimination. Study findings have implications for examining Latinx youth ethnic identity development in new destination communities.

Keywords: Latinx, discrimination, ethnic identity, ethnic labels, families
\end{abstract}

\section{Introduction}

Latinx (i.e., Latino males and females) youth (under 18 years of age) are one of the fastest growing groups of youth in the United States (Colby \& Ortman, 2015). The number of Latinx youth in the U.S. more than doubled between 1993 and 2013 (Krogstad, 2014) and census projections estimate that Latinx youth will comprise nearly $30 \%$ of the total U.S. population by 2060 (Colby \& Ortman, 2015). In the last decade, the dispersion of the Latinx population across the U.S. has resulted in rapid growth in the number of Latinx individuals in communities that had previously not had many Latinx residents. Many of these "new Latinx destination communities" are in southern U.S. states (Stepler \& Lopez, 2016).

Recent studies have found that youth living in these new Latinx destination communities have unique experiences, challenges, and needs (e.g., Brietzke, \& Perreira, 2016; Gonzalez, Stein, \& Huq, 2013). For example, youth and their families in these communities are faced with a lack of bilingual resources in school and medical settings (Corona, Gonzalez, Cohen, Edwards, \& Edmonds, 2009), and express concerns about discrimination (Perreira, Fuligni, \& Potochnick, 2010). As such, understanding youths' experiences in these new Latinx communities is important because they may affect normative developmental processes that have primarily been explored among Latinx youth living in communities with a large and established Latinx population.

In the current study, we were specifically interested in better understanding youths' feelings about their ethnic group (i.e., ethnic affirmation), the contextual factors that may affect their feelings, and the ethnic labels they choose to describe themselves (i.e., self-identification). Affirmation and selfidentification are two components of ethnic identity, which is an important developmental process for racial/ethnic minority youth (Knight, Bernal, Garza, Cota, \& O'campo, 1993; Phinney \& Rosenthal, 1992). A positive ethnic identity is directly and indirectly associated with improved physical and mental health and academic outcomes (see Rivas-Drake et al., 2014; Ugurlu \& Ozfidan, 2015). Yet, current findings suggest that ethnic identity processes may be different for youth in new Latinx destinations (Gonzalez, 
Stein, \& Huq, 2013). Thus, it is important to identify how youth in new Latinx destinations feel about their ethnic group and contextual factors that may affect their ethnic affirmation. This type of information may help individuals working with Latinxyouth in school and health settings in new Latinx destination communities.

\section{Ethnic Identity Development among Latinx Youth}

Ethnic identity is a psychological construct that reflects various aspects of identification with and membership in an ethnic group (Knight, Bernal, Garza, Cota, \& Ocampo, 1993; Phinney \& Rosenthal, 1992; Ozfidan, Machtmes, \& Demir, 2014). The salient components of ethnic identity include selfidentification, feelings of belongingness and commitment to a group, and a sense of shared values and attitudes towards one's ethnic group (Phinney, 1989; Rivas-Drake et al., 2014). A robust finding in the literature is that a strong ethnic identity has a direct and indirect effect on Latinx youths' physical and mental health, and academic outcomes (Rivas-Drake et al., 2014; Zapolski, Fisher, Banks, Hensel, \& Barnes-Najor, 2016). The health promoting indirect effect is demonstrated in studies that have found that a strong ethnic identity mitigates the effect of cultural stressors (e.g., acculturative stress, discrimination) on Latinx youths' outcomes (Acosta, Hospital, Graziano, Morris, \& Wagner, 2015; Brittian et al., 2015; RivasDrake et al., 2014; Umaña-Taylor, Wong, Gonzales, \& Dumka, 2012).

Building on the recommendations of Rivas-Drake and colleagues (2014), who argued for the importance of distinguishing between ethnic identity dimensions rather than using a composite score, recent work has found that the different components of ethnic identity may be differentially related to Latinx youth's health and educational outcomes (Brittian et al., 2015; Umaña-Taylor, Wong, Gonzales, \& Dumka, 2012) and that they may follow different developmental pathways (Rivas-Drake et al, 2014).

Much of the literature on Latinx youths' ethnic identity has focused on ethnic identity affirmation, which is defined as individuals' positive attitudes and sense of belonging to their ethnic group (RivasDrake et al., 2014). Relative to other components of ethnic identity, the ethnic labels (i.e., selfidentification) that youth use to describe their racial/ethnic background have received relatively less attention in the literature (Faltis, 2014). Yet, how youth identify can change over time and these changes may be related to contextual factors such as the number of similar co-ethnic peers in one's community. For example, Nishina, Bellmore, Witkow, and Nylund-Gibson (2010) found that ethnic self-labels remained stable over time for about $60 \%$ of a middle school sample and Eschbach and Gómez (1998) found consistency in ethnic self-identification in about $68 \%$ of Latinx sophomore students.

As youth spend more time in the U.S. there may also be a move towards the adoption of more American labels (Fuligni, Kiang, Witkow, \& Baldelomar (2008); alternatively, societal factors (e.g., fewer co-ethnic peers in a community, immigration debates) could also lead youth to more closely identify with their ethnic group (Geerlings, Verkuyten, \& Thijs, 2015). In a longitudinal study examining racial/ethnic labeling among youth from immigrant families living in communities with a large number of similar coethnics, Fuligni, Kiang, Witkow, and Baldelomar (2008) found that second-generation youth were more likely than first generation youth to include a pan-ethnic or American label in describing their ethnic background. While this study focused on racial/ethnic minority youth living in a community with a large number of similar co-ethnic peers, the authors hypothesized that youth from immigrant families living in areas with fewer similar co-ethnics may show higher levels of pan-ethnic and American labeling. In this manuscript, we explore this hypothesis in a sample of Latinx youth living in a new destination community.

As noted earlier, a robust finding in the literature is that ethnic affirmation promotes positive physical and mental health, and educational outcomes (Rivas-Drake et al., 2014). For example, researchers have found that Latinx youth with increased levels of closeness (i.e., ethnic affirmation, pride) towards their ethnic group exhibit higher levels of daily happiness, less daily anxiety, greater self-esteem, and higher academic achievement (Kiang, Yip, Gonzales-Backen, Witkow, \& Fuligni, 2006; Supple, Ghazarian, Frabutt, Plunkett, \& Sands, 2006; Umaña-Taylor, Diversi, \& Fine, 2002). Research has also noted a negative association between ethnic affirmation and Latinx youth substance use and sexual risk behaviors (Acosta et al., 2015).

To date, much of what we know about Latinx youths' ethnic identity development, and its relation to health and educational outcomes, comes from research studies that were conducted in communities where there are large numbers of Latinx families who have lived there for multiple generations (e.g., Serrano-Villar \& Calzada, 2016; Umaña-Taylor, Zeiders, \& Updegraff, 2013). We know relatively less about this normative developmental process among Latinx youth living in new Latinx destination communities. Yet, research has demonstrated that the numbers of similar co-ethnic peers in one's school 
and/or community affects ethnic identity development (e.g., Supple et al., 2006), the relationship between ethnic identity and health outcomes (e.g., Brittian, Umaña-Taylor, \& Derlan, 2013), and parental ethnic socialization practices that contribute to Latinx youth's ethnic identity development (Umaña-Taylor \& Fine, 2004). Research on ethnic identity among Latinx adolescents in new Latinx destinations has noted that ethnic identity may not always promote health and educational outcomes. In fact, Gonzalez, Stein, and Huq (2013) reported a negative association between ethnic private regard (i.e., how adolescents' feel about their ethnic group) and educational aspirations. Together, these studies highlight the importance of developing a better understanding of ethnic identity processes among Latinx youth living in new Latinx destinations.

\section{Present Study}

We used semi-structured interviews to better understand the experiences of Latinx families living in a new Latinx destination community. Families lived in a Southeastern community that, in the past, had few Latinx residents, but is currently undergoing a rapid increase in the Latinx population. Specifically, the Latinx population in this community increased by $106 \%$ between 2000 and 2012 (Brown \& Patten, 2014); with a higher percent increase in some counties/cities. Qualitative data on ethnic identity self-identification and affirmation were collected as part of a larger qualitative study that explored youths' hopes and fears for their future, experiences translating and interpreting for parents, family relationships, and ethnic identity and socialization practices. In this manuscript, our two main research questions were (a) what ethnic labels do Latinx youth living in new destination communities use to describe their ethnic background; and (b) how do Latinx youth feel about being Latinx? We were specifically interested in identifying youths' positive feelings about their ethnic group (i.e., ethnic affirmation) and also contextual factors or experiences that may affect their ethnic affirmation. Data from parents were used to triangulate the findings from the youths' transcripts and to provide a more holistic description of emergent themes and increase reliability of the findings (Patton, 2002).

\section{Methods}

\section{Participants}

Twenty-five Latinx youth and their parents ( $n=18$ mothers, 11 fathers) participated in a study on Latinx family relationships and youth development. Youth were eligible to participate if they were between the ages of 10-16 years, lived with their parents, and had their parents' permission to participate. All youth between the ages of 10 and 16 years in a household were eligible to participate. All parental caregivers (e.g., mothers and fathers, mothers and grandmothers) of eligible youth were invited to participate in the study. Parents were 18 biological mothers and 11 biological fathers. See Table 1 for a breakdown of family composition. 
Rosalie Corona, Efren Velazquez, Shelby E. McDonald, Melissa Avila, Molly Neff, Adam Iglesias and Raquel Halfond

Table 1 Family Composition

\begin{tabular}{ll} 
Family ID & Family Members Interviewed \\
\hline Family 1 & Mother, son \\
Family 2 & Mother, father, son \\
Family 3 & Mother, father, daughter \\
Family 4 & Mother, father, daughter \\
Family 5 & Mother, daughter \\
Family 6 & Mother, father, son \\
Family 7 & Mother, daughter \\
Family 8 & Mother, father, daughter, son \\
Family 9 & Mother, daughter \\
Family 10 & Mother, daughter, son \\
Family 11 & Mother, father, son \\
Family 12 & Mother, father, daughter, daughter, daughter \\
Family 13 & Mother, father, son, daughter \\
Family 14 & Mother, son, daughter \\
Family 15 & Mother, father, son \\
Family 16 & Mother, son \\
Family 17 & Mother, father, son \\
Family 18 & Mother, father, daughter, daughter \\
\hline
\end{tabular}

Twenty-five Latinx youth (14 girls, 11 boys) participated. Youth ranged in age from 10 to 15 years, with a mean age of $12.4(S D=1.78)$. Fourteen youth self-identified as an immigrant to the United States; 11 youth were born in the U.S. Among youth identifying as immigrants, countries of origin included: Mexico $(\mathrm{n}=10)$, Ecuador $(\mathrm{n}=1)$, the Dominican Republic, $(\mathrm{n}=1)$, Venezuela $(\mathrm{n}=1)$, and Colombia $(\mathrm{n}=1)$. The amount of time immigrant youth lived in the U.S. ranged from less than a year to 14 years. Among U.S.-born youth, 10 reported having at least one parent born outside the U.S. (Cuba, the Dominican Republic, Ecuador, El Salvador, Puerto Rico, and Venezuela) and one had two parents who were born in the U.S.

Eighteen mothers and eleven fathers participated in the study. The majority of parents were immigrants ( $78 \%$ of mothers and $91 \%$ of fathers). Immigrant parents had spent an average of 10 years in the United States. Most of the immigrant parents were from Mexico with other immigrant parents from Ecuador, El Salvador, Dominican Republic, Colombia, Venezuela, Cuba, and Puerto Rico.

\section{Data Collection}

Research team. The research team was comprised of a faculty member, seven doctoral students in clinical and counseling psychology programs, and two undergraduate psychology majors. Seven research team members were of Latinx descent (Mexican, Puerto Rican, Honduran, and Cuban) while three were of 
European-American descent. The majority of team members were bilingual in Spanish and English (only one European-American team member was not bilingual). The research team members participated in data collection and analysis, and bilingual team members translated study materials. The translation team was comprised of bilingual Latinx (Honduran, Cuban, Puerto Rican) doctoral students enrolled in either the clinical or counseling psychology program at a state university. All had prior experience in document translation and back-translation and were supervised by a bilingual faculty member of Mexican descent. The heterogeneity of Latinx on our research team provided us with an opportunity to address differences in language among Latinx sub-groups.

Study material translation. Study materials (e.g., consent form, short demographic survey, semistructured interview) were translated from English into Spanish using a combination of the translation by committee and back-translation approaches (Knight, Roosa, \& Umaña-Taylor, 2009; Sireci, Yang, Harter, \& Ehrlich, 2006). Specifically, study materials were first translated into Spanish; a second translator reviewed the Spanish translations and a third person (i.e., translation by committee) resolved any discrepancies. As a final check, study materials were back-translated into English by a third translator and translations were reviewed by our community partner.

Participant recruitment. Once all study measures were translated and human subjects approval was received, the research team began to recruit participants into the study. Participants were recruited through flyers posted at local community organizations and apartment complexes with a large number of Latinx residents. Research staff also visited local churches with large Latinx denominations to distribute flyers and describe the study to interested individuals. Individuals interested in participating were instructed to call the research offices. During the initial phone call, a bilingual research assistant described the study and set an interview date. On the day of the interview, bilingual research staff reviewed assent forms with the youth and answered questions. Parents provided permission for their youth's participation and youth assented to participate in the study.

\section{Measures}

Semi-structured interviews. After participants consented/assented, family members were taken to separate rooms to participate in semi-structured interviews. Bilingual research assistants used a semistructured protocol (see Table 2) to conduct the interviews. Interview topics were open-ended and broad. Interviews were conducted in English and/or Spanish based on participant preferences. Fifty-six percent of the youth interviews were conducted in English, 40\% were conducted in Spanish, and 4\% were conducted in both Spanish and English. Most parents (72\%) completed the interviews in Spanish. Interviews lasted approximately 45 minutes and were audio recorded. All participants received a $\$ 20$ gift certificate for participation.

Table 2 Semi-structured interview questions

Youth Questions Where were you born?
Parent Questions

Where were you born?

Probe: If parent was not born in the U.S., ask, "Tell me a little about why you came to the United States?" "Tell me a little about how you got here and what that journey was like for you and your family." "What types of things did you encounter on your journey?"

How long have you lived in the United States?

Where were your children born?

Where was your father born? 
What word(s) would you use to describe your racial How do you feel being Latino/Hispanic? or ethnic background?

Probe:If child has trouble, say, "Jennifer Lopez (J

Lo) might say she is Latina or Hispanic or Puerto

Rican; Martin Luther King might say he is black or

African American."

How do you feel being [child's ethnic background]?

Tell me some good things about Latino/Hispanic?

Tell me some good things about being [child's ethnic background]?

Tell me something about when or why it might be hard to be [child's ethnic background].
How do your try to teach your child about your ethnic or cultural background?

What do you say to your children about being Latino or Hispanic?

\section{Data Coding and Analysis Plan}

Bilingual research staff transcribed audio recordings of the interviews. Once an audio recording was transcribed, a different bilingual research assistant checked to ensure the transcript matched the audio recording. Transcripts were uploaded and managed with a qualitative data analysis program (QSRNVivo7, 2006), which allowed us to link the themes to the text.

Ethnic labels. Youths' descriptions of their racial/ethnic background were assigned to three categories independently by two coders following the ethnic label coding described by Fuligni et al. (2008): (a) national origin (e.g., Mexican, Colombian); (b) pan-ethnic terms (e.g., Latino, Hispanic); (c) American term by itself or hyphenated (e.g., Mexican-American, American). Four youth replied by providing a national origin and pan-ethnic label, with a pause between the first and second label. For example, a boy replied, "Mexican. [pause]. Latino." In these instances, both responses were coded in their individual categories (e.g., national origin, pan-ethnic) so the total number of responses is greater than the total number of participants in the study. We calculated Cohen's Kappa (Cohen, 1960) to check consistency between the coders and all codes showed good internal consistency $(>.80)$.

Ethnic identity affirmation and contextual factors. In this study, we were specifically interested in identifying youths' positive feelings about their ethnic group (i.e., ethnic affirmation) and also contextual factors or experiences that may contribute to negative feelings about their ethnic group. Using a thematic analysis approach (Braun \& Clark, 2006) coding followed six sequential steps. First, the two, bilingual coders (who also served as interviewers) familiarized themselves with the data by reading through each parent and youth transcript. Specifically, the bilingual coders initially read through the transcripts to identify the presence of text related ethnic identity affirmation (i.e., individual's positive sense of belonging, closeness, and positive attitudes about their ethnic group). In addition to identifying text related to ethnic-affirmation, coders also familiarized themselves with text that described contextual factors (e.g., problems they encountered or experienced because they are Latinx). Second, the coders created a set of initial codes and developed a codebook of themes using both inductive and deductive techniques. That is, themes were derived from the prior literature and the text itself. Qualitative codebooks, similar to quantitative codebooks, list each theme and sub-theme accompanied by a detailed description, inclusion and exclusion criteria, and exemplars (i.e., typical examples). In developing the codebook of themes, the coders looked for metaphors, repetitions across informants, and shifts in content that indicated relevant themes (Strauss \& Corbin, 1990). Third, the two coders met to become familiar with a set of standardized procedures for marking chunks of text that pertained to each theme and then searched within the transcripts for the themes. As part of this step, the coders each coded all of the transcripts. Fourth, the coders met and reviewed the coded transcripts for agreement and discrepancies in their assignment of themes to the data. Disagreements between the coders were discussed and resolved by consensus (Hill, Knox, Thompson, Williams, Hess, \& Ladany, 2005). Fifth, the coders met again to review the themes and decided upon names for the themes and how they related to one another, including how parent responses could be used to triangulate the experiences from the youth. 


\section{Results}

\section{Ethnic Labels}

The most frequently used labels were pan-ethnic (36\%), followed by national origin terms $(28 \%)$, and American terms (with or without a pan-ethnic/national origin label) (16\%). Four (16\%) youth replied by providing a national origin and pan-ethnic label with a pause between the first and second label and one youth (4\%) did not provide a self-label. Table 3 shows the labels provided by participants (youth were given a pseudonym). Although immigrant and U.S.-born youth used labels in each category, 60\% of immigrant youth (compared to $18 \%$ of U.S.-born youth) used a national origin label alone or in combination with a pan-ethnic term to describe their racial/ethnic background. The majority of U.S.-born youth $(80 \%)$ used a pan-ethnic term alone or in combination with an American term.

Table 3The ethnic labels used by 25 Latino youth to describe their racial/ethnic background

\begin{tabular}{|c|c|c|c|c|c|}
\hline Name & Age & Gender & Nativity & Family country of origin & Self-Label \\
\hline \multicolumn{6}{|c|}{ Pan-Ethnic $(n=9)$} \\
\hline Roberto & 10 & $\mathrm{M}$ & Immigrant & Mexico & Latino \\
\hline Luis & 11 & $\mathrm{M}$ & Immigrant & Colombia & Hispanic \\
\hline Juana & 12 & $\mathrm{~F}$ & Immigrant & Mexico & Hispanos \\
\hline Sasha & 13 & $\mathrm{~F}$ & Immigrant & Mexico & Hispana \\
\hline Victor & 12 & $\mathrm{M}$ & U.S.-born & Puerto Rico & Spanish \\
\hline Steven & 13 & $\mathrm{M}$ & U.S.-born & Dominican Republic & Latino \\
\hline Junot & 15 & M & U.S.-born & Dominican Republic & Latino \\
\hline Vivian & 15 & $\mathrm{~F}$ & U.S.-born & Puerto Rico & Hispanic \\
\hline Rosa & 15 & $\mathrm{~F}$ & U.S.-born & Ecuador & Hispanic; Latino \\
\hline \multicolumn{6}{|c|}{ National Origin $(n=7)$} \\
\hline Juan & 10 & M & Immigrant & Mexico & Mexicano \\
\hline Ricardo & 10 & $\mathrm{~F}$ & Immigrant & Mexico & Mexicana \\
\hline Luisa & 11 & $\mathrm{~F}$ & Immigrant & Mexico & Mexicana \\
\hline Cecily & 13 & $\mathrm{~F}$ & Immigrant & Venezuela & Venezuelan \\
\hline Kassandra & 13 & $\mathrm{~F}$ & Immigrant & Mexico & de Mexico \\
\hline Cristina & 15 & $\mathrm{~F}$ & Immigrant & Dominican Republic & Dominican \\
\hline Isabela & 13 & $\mathrm{~F}$ & U.S-born & Cuba & Cuban \\
\hline \multicolumn{6}{|c|}{ Pan-Ethnic \& National Origin Combined $(n=4)$} \\
\hline Emiliano & 13 & M & Immigrant & Mexico & Hispano; Mexicano \\
\hline Olivia & 14 & $\mathrm{~F}$ & Immigrant & Ecuador & $\begin{array}{l}\text { Ecuatoriana; Hispana; } \\
\text { Latina }\end{array}$ \\
\hline Efren & 15 & $\mathrm{M}$ & Immigrant & Mexico & Mexicano; Hispano \\
\hline Alejandra & 13 & $\mathrm{~F}$ & U.S-born & Ecuador & Latina; Ecuadorian \\
\hline \multicolumn{6}{|c|}{ American* $(n=4)$} \\
\hline Adriana & 11 & $\mathrm{~F}$ & Immigrant & Mexico & Mexicana Americana \\
\hline Mayra & 10 & M & U.S.-born & Ecuador & American \\
\hline Ingrid & 11 & $\mathrm{~F}$ & U.S.-born & El Salvador & Spanish American \\
\hline Diego & 12 & M & U.S.-born & Cuba & Latino American \\
\hline \multicolumn{6}{|c|}{ No Label Provided $(\mathrm{n}=1)$} \\
\hline Pablo & 10 & M & U.S.-born & Venezuela & \\
\hline
\end{tabular}

* American terms were coded when they were given alone or in combination with another term (e.g., Mexican American).

\section{Ethnic Affirmation and Contextual Factors}

One theme emerged related to Latinx youths' ethnic affirmation (i.e., their positive attitudes and feelings about their ethnic group): (Theme 1) "Me siento orgulloso." ("I feel proud."). Latinx youths' pride in their culture was further explained by two emergent sub-themes, specifically, (1a) pride in speaking two languages and (1b) pride in cultural objects and experiences. Two themes emerged related to contextual factors that may affect youths' feelings of affirmation within the context of a new Latinx community: (Theme 2)“Dificultad en comunicarse."(“communication difficulties."); and (Theme 3) "Hay mucho discriminación." ("There is a lot of discrimination."). 
Theme 1: Me siento orgulloso (I feel proud). Latinx youth in this study reported feeling proud of their cultural background, especially in their ability to speak two languages. Some youth described feeling pride because speaking in Spanish allowed them to talk to family members and peers privately. A 13-yearold girl said, "When I speak Spanish with a few of my Latinx friends, like they're [friends who don't speak Spanish] totally out of the conversation, and I think that's fun." An 11-year-old girl said, "If I have to talk to my mom about something personal, and I don't want my friends to know, I can talk to my mom about it in Spanish and my friends won't know." Finally, a12-year-old girl said she liked having two perspectives "a Hispanic point of view" and an "American viewpoint." Some youth also shared that pride in their bilingualism was fostered by their parents. For example, a 12-year-old boys hared that his parents told him, "It's a great thing [to be Latino]... it's very good because you can speak Spanish and English and you can get better job offers and stuff like that."

Other aspects of the culture that youth felt pride in included playing soccer, Latin food and music, visiting their native country, holiday traditions, and family. For example, a 12-year-old boy stated: "I like all the food that we get to eat, and Spanish is a cool language to learn, and there's lots of holidays and places to go and stuff like that." A 12-year-old girl said, "Pues para mí es que tengo mí familia - mi mama, mi papa, mis hermanos, mi abuelita." ("Well, for me, it is that I have my family - my mom, my dad, my brothers, my grandmother.") Having family around was important because family could help youth learn about their culture. For example, a 15-year-old girl shared that her grandmother tells her about Ecuador's culture and landscape: "My grandma, since she's here, she's talked about Ecuador, about the mountains, about...the country in general."

Finally, youth reported that their parents often shared with them the uniqueness of their cultural group. For example, a 13-year-old girl said that her parents told her "Oh, it's [Cuban music] so different from everything else. We're so lucky." Similarly, a 15-year-old girl reported "They teach us like about the food and sometimes the legends, um the books, and the dancing, and the music. They teach us about everything." Youth and parents shared that their parents also decorated their home with objects representing their native country, such as paintings, religious figures, books, and other traditional pieces, as a way of exposing youth to their culture and maintaining their cultural ties.

Triangulation: Parents' also noted that they encouraged their youth to take pride (e.g., "debe de ser orgulloso.") in their ethnic group and their bilingualism. For example, a father shared, "Hoy día disfrutan de poder hablar español como lo hablan."("Nowadays they enjoy speaking Spanish the way they do.") Many parents also noted that they, too, were proud to be Latinx. For example, one mother shared, "I guess when I was younger you know there was such a prejudice against Hispanic or you know, like this native feeling, but now I'm proud that I'm Hispanic." Parents also told their youth that being bi-cultural was special and shared their culture with them through travel, home decorations, games (e.g., Lotería) music, and family and cultural traditions. A mother noted, "Le digo que es importante que ella trata de hablar en español. Le digo lo que ser hispana ella la hace una persona especial, porque no es como todas las de mas personas sino que tiene más porque tiene dos culturas, tiene una cultura Hispana."("I tell her that it is important that she try to speak Spanish. I tell her that being Hispanic makes her a special person, because she is not like the rest of the people, rather she has two cultures, she has a Hispanic culture.")

Theme 2: Dificultad en comunicarse (communication difficulties). While the youth expressed pride in their bilingualism and cultural group, some also mentioned problems related to communication difficulties with family members, other Americans, and in school. For example, a 14-old girl stated: "Con los Hispanos mismo sí me comunico muy bien. Pero con los, con los de aquí es un poco más difícil." ("I communicate well with other Hispanics, however, with the people from here it is a little more difficult.") In addition, a 10-year-old girl said that being in school is difficult because she does not know English and as a result, she has trouble doing her homework and understanding her teacher. Youth also mentioned how others made assumptions about their language abilities because of their ethnicity. For example, a 13-yearold girl stated:

Um, the only part is that when I came to the USA I had to go to ESL, so being from another race, people, English teachers think like, 'no she doesn't know enough English ... She's not going to do well in this class', so that they send you to an ESL [class]. And that's something that bothers me. It's like just because you're from another race doesn't mean you don't know English.

Triangulation: Parents talked about communication difficulties in their families when parents 
primarily spoke Spanish and youth spoke (or wanted to speak) English. Parents also noted communication difficulties experienced by youth and families in school settings. One mother shared this story about her daughter and husband:

"Recién llegamos acá en Virginia, mi niña vio que nadie hablaba español. Entonces mi esposo fue por ella y hablo en español. Mi hija dijo, 'Papi no, no habla español, que pena papi, no vaya hablar español.' Aah, no él dijo. Usted no me va a callar mamita, yo soy, yo soy Colombiano, y soy muy orgulloso de ser Colombiano, y nadie me va a decir que no hable español."("We just arrived in Virginia, my daughter saw that no one spoke Spanish. Then my husband went after her and spoke in Spanish. My daughter said, 'Papi no, do not speak Spanish, what a pity papi, do not go speak Spanish.' "Aah, no," he said. "You are not going to shut me up, I am, I am Colombian, I am very proud to be Colombian, and nobody is going to tell me not to speak Spanish.”)

Theme 3: Hay mucho discriminación ("There is a lot of discrimination"). Youth also reported that being stereotyped and discriminated against was something they did not like, especially as people made assumptions that because they were Latinx they were Mexican. A 15-year-old girl said, "I think people when they see a Latino they usually think they're Mexican or something like that ...and so I mean we just have to correct them, and tell them that it's not only when you see a Hispanic person they think its Mexican. There's also other countries." Similarly, a 15-year-old girl said, "Sometimes just being Hispanic in general, people are like 'oh stupid Mexican' or something like that and that makes me really sad because people then just don't understand my culture and people don't understand what it is about me that I think makes me special. And they just kind of shoot it down immediately." Finally, a 13-year-old girl reported: "I know that some kids at my school get um racial slurs. Like if they're Mexican like some guys will go " hey when did you just jump over the border' ... and it will be really harmful, and like when they're making fun of the Mexicans or other, or other um Hispanics I'll be like 'you know hey I'm Hispanic and I don't think that you should really be doing that."”

Triangulation: Parents also echoed these same sentiments. For example, one mother noted, "Un niño moreno, cuando el [her son] estaba en la escuela el año pasado, le dijo que era un, un Mexicano espalda mojada."(“A Black kid, when he [her son] was in school last year, called him a, a Mexican wetback.") Another mother said, "You know, some people have been stereotyped that you know, we're [Latinos] not that smart or we do dumb things or, [are] low class." Finally, one mother shared, "Les digo que tienen que trabajar doblé, no pueden conformarse. Por ejemplo ser buenos, tienen que ser los mejores, porque yo quiero que ellos tratan de borrar esa imagen que hay en este país, tan negativa del Hispano."("I tell them that they have work twice as hard, they cannot conform. For example, to be good, they have to be the best, because I want them to erase that negative image of the Hispanic that is in this country.")

\section{Discussion}

There is an extensive literature emphasizing the importance of positive ethnic identity development, specifically ethnic affirmation, on Latinx youth's health and educational outcomes (e.g., Rivas-Drake et al., 2014). Much of what we have learned, however, is based on studies conducted with Latinx youth living in areas with a large, and established (i.e., community with multiple generations of Latinx families) Latinx population. Relatively less work has focused on ethnic affirmation or ethnic labels among youth living in new Latinx destination communities. Yet, how Latinx youth feel about their ethnic group (i.e., ethnic affirmation), and the labels they use to describe themselves (i.e., ethnic labels), are associated with contextual factors such as the number of similar co-ethnics in one's community and school (e.g., Fuligni et al., 2008; Supple et al., 2006). Using qualitative methodology, this study sought to address this gap in the literature.

In this qualitative study, Latinx youth living in a new Latinx destination community used a variety of labels to describe their racial/ethnic background. Slightly over half of the youth in this study used a panethnic term (alone or in combination with another label) to describe their racial/ethnic background. However, only four youth used an American term. Perhaps youth living in an area with a less-dense Latinx population use labels that are consistent with their perception of how the non-Latinx community views them - i.e., as "Latino" or "Hispanic" and not "American." It is also possible that because they are surrounded by fewer Latinx peers, youth in this study may have been more aware of and proud of their Latinx heritage and thus, hesitant to adopt the use of an American label. In fact, when asked what they liked about being Latinx many youth reported feeling proud of their ethnic background, especially their ability to speak two languages. We also found that a higher percentage of immigrant youth (compared to U.S.-born 
youth) used a national origin label alone or in combination with a pan-ethnic term. This finding is consistent with larger cross-sectional studies conducted in states with large Latinx populations (e.g., Doan \& Stephan, 2006; Fuligni, Witkow, \& Garcia, 2005). It has been hypothesized that immigrant youth retain a national origin term in an effort to avoid the negative stereotypes associated with pan-ethnic terms such as "Hispanic" in the United States (Matute-Bianchi, 1991).

Together, the findings on ethnic labels highlight future areas of study including developing a better understanding of how contextual factors (e.g., number of co-ethnic peers in a community or school, discrimination experiences) are associated with Latinx youths' choice of ethnic labels in describing who they are and whether these choices may change depending on context (e.g., using one label at school friends and another label with family). Moreover, whether youth in new Latinx communities change their ethnic labels over time is a question for future research. Fuligni et al (2008) found that immigrant youth changed ethnic labels from year to year. Whether this type of exploration in labels will be seen in a group of youth who live in a community with fewer Latinx peers has not been empirically explored but could potentially affect the youths' adjustment and the community's perception of Latinx youth.

Using thematic analysis, three themes emerged regarding ethnic affirmation of youth living in a new Latinx destination community. Importantly, each of these themes highlights the role of the youths' community context in their feelings about their ethnic group. Both immigrant and U.S.-born youth mentioned the discrimination and stereotypes they experienced or witnessed in their schools and community as things they did not like about being Latinx in this particular community, suggesting that these experiences may affect youths' ethnic affirmation. Youth described experiences in which peers or community members would make assumptions that all Latinx individuals were of Mexican origin. This result is consistent with Cavalcanti and Schleef's (2007) findings that non-Mexican Latinx adults living in areas with a less dense Latinx community prefer not to be assumed to be Mexican because of the stigma attached to this subset of Latinx in the U.S. Although Mexicans are the largest sub-group of Latinx in the U.S., this may not necessarily be the case in new Latinx destination communities. For example, $65 \%$ of 212 Latinx adults living in an emerging Latinx community who completed an anonymous survey were of South and Central American descent (Corona et al., 2009). Whether local community residents recognize the diversity within the Latinx community is unknown, highlighting an area of future study. Regardless, it is clear from our findings that Latinx youth perceive discrimination due to community members' generalizations and stereotypes about Latinx individuals in this new Latinx destination community, and that it may play a role in their attitudes about their ethnic group.

The findings of the salience of discrimination in the lives of the Latinx youth who participated in this study highlights the need to better understand how experiences of discrimination affect ethnic identity development and adjustment among youth in new Latinx destinations. Ethnic identity has been shown to have a protective effect on physical and mental health and educational outcomes among Latinx youth living in established Latinx communities (Kiang, Yip, Gonzales-Backen, Witkow, \& Fuligni, 2006; Supple, Ghazarian, Frabutt, Plunkett, \& Sands, 2006; Umaña-Taylor, Diversi, \& Fine, 2002). A recent study of adolescents living in a new Latinx destination found a negative association between ethnic identity and educational aspirations (Gonzalez et al., 2013). Our findings, in combination with this emerging literature, highlight a need to better understand ethnic identity development and its relation to health and educational outcomes among youth living in new Latinx destinations.

For Latinx youth living in an area where there are fewer Latinx peers, the use of a non-English language was mentioned as both a positive and negative aspect of being Latinx. Some youth reported feeling proud that they could speak two languages, and that their parents encouraged their bilingualism because it would lead to better future outcomes. On the other hand, some youth reported difficulties communicating at school and in the community. What appears to be less clear at this point is how experiences of discrimination may intersect with bilingualism in predicting Latinx youths' educational and health outcomes. We know that Latinxy outh in emerging communities may often be called on to serve as language brokers for their families and that this experience is seen both positively and negatively (Corona et al., 2012). Specifically, the experience of serving as a translator and interpreter for their parents can be stressful for some youth and may also affect how others, including their peers, perceive them. Accordingly, more research that examines the conditions under which bilingualism is positive or negative, and how it may relate to ethnic identity, is warranted.

\section{Limitations}

Although the qualitative nature of this study allows for a richer and more in depth understanding 
of Latinx youths' ethnic self-identification, affirmation and contextual factors that may affect their ethnicaffirmation, there are some limitations to the study. The current study describes the perspective and experience of twenty-five Latinx youth from diverse ethnic backgrounds living in an area with a growing Latinx population. Moreover, the diversity within the Latinx ethnic group and the political atmosphere surrounding immigration in this community limit the generalizability of the findings.

\section{New Contributions to the Literature}

Despite these limitations, this study highlights two contextual factors (communication difficulties and discrimination) that may be particularly relevant to ethnic identity development for Latinx youth living in new Latinx destination communities. More work is needed that explores whether and how these processes may influence ethnic identity self-identification and affirmation, and in turn, how ethnic identity components are related to youths' physical and mental health, and academic outcomes. An emerging literature suggests that ethnic identity components for youth in new Latinx communities may not be related to outcomes in the same way as they are for youth in Latinx communities with a larger number of Latinx individuals that have lived in the community for multiple generations (Gonzalez et al., 2013). In sum, given the dispersion of and rapid growth of the Latinx population in new Latinx communities, it is important that we explore whether normative identity processes follow similar developmental pathways as found in communities with more Latinx co-ethnics. Moreover, we need to explore whether there are unique relationships among ethnic identity components and outcomes for Latinx youth in these new Latinx communities.

\section{Grant Funding}

This project was supported by a grant from Virginia Commonwealth University's Council for Community Engagement. It's contents are solely the responsibility of the authors and do not necessarily represent official views of Virginia Commonwealth University and/or the Council for Community Engagement.

\section{Acknowledgement}

We would like to thank the families who shared their experiences and time with us, our community partners who supported the project, and Ms. Ivette Santiago who provided guidance regarding participant recruitment. We are also thankful to Anya Moon, Karen Mendez, Karin DeLeon, and Mauricio Taborga who helped with data collection and transcription.

\section{References}

Acosta, S. L., Hospital, M. M., Graziano, J. N., Morris, S., \& Wagner, E. F. (2015). Pathways to drinking among Hispanic/Latino adolescents: perceived discrimination, ethnic identity, and peer affiliations. Journal of ethnicity in substance abuse, 14, 270-286.

Braun, V. \& Clarke, V. (2006). Using thematic analysis in psychology. Qualitative Research in Psychology, 3(2),77-101. doi:10.1191/1478088706qp063oa

Brietzke, M., \& Perreira, K. (2016). Stress and Coping Latino Youth Coming of Age in a New Latino Destination. Journal of Adolescent Research. doi:10.1177/0743558416637915.

Brittian, A. S., Umaña-Taylor, A. J., \& Derlan, C. L. (2013). An examination of biracial college youths' family ethnic socialization, ethnic identity, and adjustment: Do self-identification labels and university context matter?. Cultural Diversity and Ethnic Minority Psychology, 19, 177-189. doi: $10.1037 / \mathrm{a} 0029438$

Brittian, A. S., Kim, S. Y., Armenta, B. E., Lee, R. M., Umaña-Taylor, A. J., Schwartz, S. J., \& Castillo, L. G. (2015). Do dimensions of ethnic identity mediate the association between perceived ethnic group discrimination and depressive symptoms?. Cultural Diversity and Ethnic Minority Psychology,21(1), 41-53. doi:10.1037/a0037531

Brown, A., \& Patten, E. (2014). Statistical Portrait of Hispanics in the United States, 2012.Retrieved from Pew Research Center website:http://www.pewhispanic.org/2014/04/29/statistical-portrait-ofhispanics-in-the-united-states-2012/

Cavalcanti, H. B., \& Schleef, D. J. (2007). Changing patterns of migration? The Latinxexperience in Richmond, Virginia. In S. Poulson (Eds.), Social issues in a global context(pp. 65-80). Upper Saddle River, NJ: Pearson-Prentice Hall.

Cohen, J. (1960). A coefficient of agreement for nominal scales. Educational and Psychological 
Rosalie Corona, Efren Velazquez, Shelby E. McDonald, Melissa Avila, Molly Neff, Adam Iglesias and Raquel Halfond

Measurement, 20(1), 37-46. doi:10.1177/001316446002000104

Colby, S. L., \& Ortman, J. M. (2015). Projections of the size and composition of the US population: 2014 to 2060. Retrieved from U.S. Census Bureau website: https://www.census.gov/content/dam/Census/library/publications/2015/demo/p25-1143.pdf

Corona, R., Gonzalez, T., Cohen, R., Edwards, C., \& Edmonds, T. (2009). Richmond Latinx needs assessment: A community-university partnership to identify health concerns and service needs for Latinx youth. Journal of Community Health, 34, 195-201. doi:10.1007/s10900-008-9140-6

Corona, R., Stevens, L.F., Halfond, R.W., Shaffer, C.M., Reid-Quiñones, K., \& Gonzalez, T. (2012). A qualitative analysis of what Latino parents and adolescents think and feel about language brokering. Journal of Child and Family Studies, 21, 788-798.

Doan, G. O., \& Stephan, C. W. (2006). The functions of ethnic identity: A New Mexico Hispanic example. International Journal of Intercultural Relations,30, 229-241.doi:10.1016/j.ijintrel.2005.07.009

Eschbach, K., \& Gomez, C. (1998). Choosing Hispanic identity: Ethnic identity switching among respondents to high school and beyond. Social Science Quarterly, 74-90. Retrieved from http://www.jstor.org/stable/42863768

Faltis, C. (2014). Toward a Race Radical Vision of Bilingual Education for Kurdish Users in Turkey: A Commentary. Journal of Ethnic and Cultural Studies, 1(1), 1-5.

Fuligni,, A. J., Witkow, M., \& Garcia, C. (2005). Ethnic identity and the academic adjustment of youth from Mexican, Chinese, and European backgrounds. Developmental Psychology, 41, 799-811. doi:10.1037/0012-1649.41.5.799

Fuligni, A.J., Kiang, L., Witkow, M.R , \& Baldelomar, O. (2008).Stability and change in ethnic labeling among youth from Asian and Latin American immigrant families. Child Development, 79, 944956. doi:10.1111/j.1467-8624.2008.01169.x

Geerlings, J., Verkuyten, M., \& Thijs, J. (2015). Changes in Ethnic Self-Identification and Heritage Language Preference in Adolescence A Cross-Lagged Panel Study. Journal of Language and Social Psychology, 34, 501-520. doi:10.1177/0261927X14564467

Gonzalez, L. M., Stein, G. L., \& Huq, N. (2013). The influence of cultural identity and perceived barriers on college-going beliefs and aspirations of Latino youth in emerging immigrant communities. Hispanic Journal of Behavioral Sciences, 35, 103-120. doi:10.1177/0739986312463002

Hil, C. E., Knox, S., Thompson, B. J., Williams, E. N., Hess, S. A., \& Ladany, N. (2005).Consensual qualitative research: An update. Journal of Counseling Psychology.52, 196-205.doi:10.1037/00220167.52 .2 .196

Kiang, L., Yip, T., Gonzales-Backen, M., Witkow, M., \& Fuligni, A. J. (2006). Ethnic identity and the daily psychological well-being of youth from Mexican and Chinese backgrounds. Child Development, 77, 1338-1350. doi:10.1111/j.1467-8624.2006.00938.x

Knight, G. P., Bernal, M. E., Garza, C. A., Cota, M. C., \& O’Campo, K. A. (1993). Family socialization and the ethnic identity of Mexican American youth. Journal of Cross-Cultural Psychology, 24, 99114. doi:10.1177/0022022193241007

Knight, G. P., Roosa, M. W., \& Umaña-Taylor, A. J. (2009).Studying ethnic minority and economically disadvantaged populations: Methodological challenges and best practices. Washington D.C., U.S.: American Psychological Association, HathiTrust Digital Library.

Krogstad, J. M. (2014). 11 facts for National Hispanic Heritage Month. Retrieved from Pew Research Center website: http:/www.pewresearch.org/fact-tank/2014/09/16/11-facts-for-national-hispanicheritage-month/

Matute-Bianchi, M. E. (1991). Situational ethnicity and patterns of school performance among immigrant and non-immigrant Mexican-descent students. In M. A. Gibson \& J. U. Ogbu (Eds.), Minority status and schooling: A comparative study of immigrant and involuntary minorities (pp. $205-$ 248). New York: Garland.

Nishina, A., Bellmore, A., Witkow, M. R., \& Nylund-Gibson, K. (2010). Longitudinal consistency of adolescent ethnic identification across varying school ethnic contexts. Developmental psychology, 46, 1389-1401. doi:10.1037/a0020728

Ozfidan, B., Machtmes, K., \& Demir, H. (2014). Socio-cultural Factors in Second Language Learning: A Case Study of Adventurous Adult Language Learners. European Journal of Education Research, 3 (4), 185-191. 
Ozfidan, B., \& Ugurlu, O. (2015). A Refugee Group's Mental Health and Social Care. Electronic International Journal of Education, Arts, and Science, 1(1), 99-114.

Patton, M. Q. (2002). Qualitative research and evaluation methods. Thousand Oaks, CA: Sage Publications, Inc.

Perreira, K. M., Fuligni, A., \& Potochnick, S. (2010). Fitting In: The roles of social acceptance and discrimination in shaping the academic motivations of Latino youth in the U.S.southeast. Journal of Social Issues, 66, 131-153. doi:10.1111/j.1540-4560.2009.01637.x

Phinney, J. S. (1989). Stages of ethnic identity development in minority group youth. Journal of Early Adolescence, 9, 34-49. doi:10.1177/0272431689091004

Phinney, J. S., \& Rosenthal, D. A., (1992). Ethnic identity in adolescence: Process context, and outcome. In G. R. Adams, T. P. Gullota, \& R. Montemayor (Eds.),Adolescent Identity Formation (pp.142-172). Newbury Park, CA: Sage Publications, Inc.

Rivas-Drake, D., Seaton, E. K., Markstrom, C., Quintana, S., Syed, M., Lee, R. M., ... \& Yip, T.(2014). Ethnic and racial identity in adolescence: Implications for psychosocial, academic, and health outcomes. Child Development, 85, 40-57. doi:10.1111/cdev.12200

Serrano-Villar, M., \& Calzada, E. J. (2016). Ethnic identity: Evidence of protective effects for young, Latino youth. Journal of applied developmental psychology, 42, 21-30. doi:10.1016/j.appdev.2015.11.002

Sireci, S. G., Yang, Y., Harter, J., \& Ehrlich, E. J. (2006). Evaluating guidelines for test adaptations: A methodological analysis of translation quality. Journal of Cross-Cultural Psychology, 37, 557-567. doi:10.1177/0022022106290478

Stepler, R., \& Lopez, M.H.(2016). U.S. Latino Population Growth and Dispersion Has Slowed Since Onset of the Great Recession. Retrieved from Pew Research Center website: http://www.pewhispanic.org/2016/09/08/latino-population-growth-and-dispersion-has-slowedsince-the-onset-of-the-great-recession/

Strauss, A., \& Corbin, J. (1990). Basics of qualitative research: Grounded theory procedures and techniques. Newbury Park, CA: Sage Publications Inc.

Supple, A. J., Ghazarian, S. R., Frabutt, J. M., Plunkett, S. W., \& Sands, T. (2006). Contextual influences on Latinx adolescent ethnic identity and academic outcomes. Child Development, 77, 1427-1433. doi:10.1111/j.1467-8624.2006.00945.x

Umaña-Taylor, A. J., Diversi, M., \& Fine, M. A. (2002). Ethnic identity and self-esteem of Latinxyouth: Distinctions among the Latinx populations. Journal of Adolescent Research, 17, 303-327. doi:10.1177/0192513X05282960

Umaña-Taylor, A. J., \& Fine, M. A. (2004). Examining ethnic identity among Mexican-origin youth living in the United States. Hispanic Journal of Behavioral Sciences, 26, 36-59. doi: 10.1177/0743558402173005

Umaña-Taylor, A. J., Wong, J. J., Gonzales, N. A., \& Dumka, L. E. (2012). Ethnic identity and gender as moderators of the association between discrimination and academic adjustment among Mexicanorigin adolescents. Journal of adolescence, 35, 773-786. doi:10.1016/j.adolescence.2011.11.003

Umaña-Taylor, A. J., Zeiders, K. H., \& Updegraff, K. A. (2013). Family ethnic socialization and ethnic identity: A family-driven, youth-driven, or reciprocal process?. Journal of Family Psychology, 27, 137-146. doi:10.1037/a0031105

Zapolski, T. C., Fisher, S., Banks, D. E., Hensel, D. J., \& Barnes-Najor, J. (2016). Examining the protective effect of ethnic identity on drug attitudes and use among a diverse youth population. Journal of youth and adolescence, 1-14. doi:10.1007/s10964-016-0605-0 